\title{
Crack Parameters Identification Based on a Kriging Surrogate Model for Operating Rotors
}

\author{
Danyang Wang, ${ }^{1}$ Chunrong Hua $\mathbb{D}^{1},{ }^{1}$ Dawei Dong, ${ }^{1}$ Biao He, ${ }^{1}$ and Zhiwen $\mathrm{Lu}^{2}$ \\ ${ }^{1}$ School of Mechanical Engineering, Southwest Jiaotong University, Chengdu, Sichuan 610031, China \\ ${ }^{2}$ The Key Laboratory of Metallurgical Equipment and Control of Education Ministry, \\ Wuhan University of Science and Technology, Wuhan 430081, China \\ Correspondence should be addressed to Chunrong Hua; hcrong@swjtu.cn
}

Received 9 May 2018; Revised 1 July 2018; Accepted 15 July 2018; Published 8 October 2018

Academic Editor: Emanuele Reccia

Copyright (c) 2018 Danyang Wang et al. This is an open access article distributed under the Creative Commons Attribution License, which permits unrestricted use, distribution, and reproduction in any medium, provided the original work is properly cited.

\begin{abstract}
Parameters identification of cracked rotors has been gaining importance in recent years, but it is still a great challenge to determine the crack parameters including crack location, depth, and angle for operating rotors. This work proposes a new method to identify crack parameters in a rotor-bearing system based on a Kriging surrogate model and an improved nondominated sorting genetic algorithm-III (NSGA-III). A rotor-bearing system with a breathing crack is established by the finite element method and the superharmonic components are used as index to detect the cracks, the Kriging surrogate model between crack parameters and the superharmonic component amplitudes of the vibration response for rotors are constructed, and an improved NSGA-III is proposed to obtain the optimal crack parameters. Numerical experiments show that the proposed method can identify the crack location, depth, and angle accurately and efficiently for operating rotors.
\end{abstract}

\section{Introduction}

Rotors are one of the most important parts of rotating machinery, which are widely used in power stations, aircraft engines, motors, and so on. Transverse fatigue crack is easily produced on rotors under bending excitation, and slant fatigue crack is generated under torsional excitation due to the harsh operation conditions. The crack propagation speed might be extremely slow at the initial stage, as the crack has propagated to a certain depth, the crack propagation speed increases sharply and the shaft may malfunction within a few hours of operation, causing a catastrophic accident [1]. In order to reduce the maintenance costs of equipment and avoid the occurrence of serious accidents, it is of enormous significance to continuously monitor the health of rotors during operation.

Many researchers have studied crack monitoring for rotors based on vibration signals [2-6], the methods can be split into two groups depending on whether the rotors are rotating or not. The crack parameter identification methods under nonoperating state of rotors are usually based on modal parameters of the cracked rotors. Dong et al. [7] established a rotor system based on wavelet finite element method and determined the position and depth of the crack by the intersection of contours of the first three natural frequencies. Haji and Olutunde Oyadiji [8] put forward the concept of orthogonal natural frequencies (ONFs) and achieved the location of cracks by calculating the ONFs at different positions of a disc. Zapico-Valle et al. [9] and $\mathrm{Yu}$ et al. [10] used the modal parameters of rotors corresponding to different crack positions and depths as the neural network input to identify rotor crack parameters. Xiang et al. [11] estimated the crack parameters by minimizing the errors of natural frequencies between simulation and experimental results. But the modal parameters used in crack identification cannot be easily obtained in operating conditions, and it is more meaningful to identify the crack parameters for rotors under operating conditions.

Generally, crack parameters identification methods for operating rotors need to test the dynamic response of the rotor. Prabhakar et al. [12] detected rotor crack during startup and shutdown of a rotor-bearing system qualitatively with continuous wavelet transform. Singh and Tiwari [13] detected the slope discontinuity in the elastic line of the shaft due to 
cracks and achieved localization of multiple cracks in a stepped shaft. Saravanan and Sekhar [14] identified the crack in a rotorbearing system utilizing the concept of operational deflection shape (ODS) and kurtosis of vibration response. Zhang et al. [15] detected the singularity of the ODS in rotors to identify the crack location and used the approximate waveform capacity dimension (AWDC) to make the singularity more prominent. Ramesh Babu and Sekhar [16] proposed a concept called amplitude deviation curve method based on ODS and realized the two cracks localization in a rotating rotor. Lu et al. [17] proposed a multicrack location method based on proper orthogonal decomposition (POD) using fractal dimension (FD) and gapped smoothing method (GSM). Lees et al. [18] reviewed the rotor crack parameter identification method based on equivalent crack forces, which treated the effects of cracks as equivalent forces exerted on a healthy rotor system. Some researchers used equivalent crack forces method to obtain the crack position and depth of rotors, such as Sekhar [19-21], Markert et al. [22], Pennacchi and et al. [23]. The second group of studies concentrates on crack detection and location for operating rotors, but it is difficult to quantitatively identify the shape and depth of the crack.

As the crack angle affects the stress, the speed of crack propagation, and fatigue life of rotors, some researchers studied the dynamic behavior of the rotor due to the slant crack [24-28]. However, there is no relevant research on crack parameters identification if crack angle is considered for operating rotors at present, transverse crack and slant crack have similar stiffness, and crack detection results could be misleading. Focusing on this challenge, the problem of crack parameters identification is transformed into multiobjective optimization problem. Then, NSGA-III $[29,30]$ is improved to obtain the optimal crack location, depth, and angle at the same time, and the Kriging surrogate model $[31,32]$ is applied to increase the optimization speed.

In this paper, a new crack parameters identification method is proposed for operating rotors using Kriging surrogate model and an improved NSGA-III. In Section 2 , the model of a rotor-bearing system with breathing cracks is constructed by the finite element method, and the influence of different crack parameters on the amplitude of superharmonic components is discussed. In Section 3, the Kriging surrogate model between crack parameters and the superharmonic component amplitudes is constructed. In Section 4, using an improved NSGA-III to predict the optimal crack parameters based on the Kriging surrogate model by minimizing the multiobjective function values related to the superharmonic components amplitudes. Numerical experiments show that the proposed method can identify the crack location, depth, and angle for operating rotors accurately and efficiently.

\section{Superharmonic Components Analysis of a Rotor-Bearing System with a Breathing Crack}

2.1. Equations of Motion of a Cracked Two-Disc Rotor-Bearing System. As shown in Figure 1, a two-disc rotor-bearing system is established by the finite element method, and the physical parameters are given in Table 1 . The shaft is discretized into 60 Timoshenko beam elements with six degrees of freedom at each node, the two discs are assumed as rigid bodies with three translational and three rotational inertias, and the gyroscopic effects of which are considered. The ball bearings are considered as linear springs and dampers.

By assembling the cracked shaft element, the uncracked shaft element, the rigid discs, and the bearings, the equation of motion of the cracked rotor system in a fixed coordinate system can be written as

$$
\begin{aligned}
\left(M_{\mathrm{s}}\right. & \left.+M_{\mathrm{r}}\right) \ddot{q}+\left[C_{\mathrm{b}}+C_{\mathrm{s}}+\Omega\left(G_{\mathrm{s}}+G_{\mathrm{r}}\right)\right] \dot{q} \\
& +\left[K_{\mathrm{b}}+K_{\mathrm{s}}+K_{\mathrm{c}}(t)\right] q=F_{\mathrm{u}}+F_{\mathrm{g}}+F_{\mathrm{ex}},
\end{aligned}
$$

where $M_{\mathrm{s}}$ and $M_{\mathrm{r}}$ are the mass matrices of the shaft and the two discs, respectively, $C_{\mathrm{s}}=\alpha M_{\mathrm{s}}+\beta K_{\mathrm{s}}$ is the shaft Rayleigh damping matrix, $C_{\mathrm{b}}$ is the damping matrix of the bearings, $\Omega$ is the rotational speed of the shaft, $G_{s}$ is the shaft gyroscopic matrix, $G_{\mathrm{r}}$ is the gyroscopic matrix of the two discs, $q$ is the displacement matrix of the node, $K_{s}$ is the stiffness matrix of the shaft, $K_{\mathrm{b}}$ is the stiffness matrix of the bearing, $K_{c}(t)$ is the stiffness matrix of the crack element, $F_{\mathrm{u}}$ is the excitation due to static unbalance of discs, $F_{\mathrm{g}}$ is the gravitational force, and $F_{\text {ex }}$ is the external excitation during operation.

Taking into account the bending and torsional coupling excitation caused by the eccentricity of the discs, the excitation acted upon the discs is

$$
\mathbf{F}_{\mathrm{u} i}=\left\{F_{\mathrm{u} x i}, F_{\mathrm{u} y i}, F_{\mathrm{u} z i}, M_{\mathrm{u} x i}, M_{\mathrm{u} y i}, M_{\mathrm{u} z i}\right\}^{T} .
$$

When rotors are rotating at a constant speed $\Omega$, the elements in $F_{\mathrm{u}}$ can be expressed as [33]

$$
\left\{\begin{array}{l}
F_{\mathrm{u} x i}=0, \\
M_{\mathrm{u} y i}=0, \\
M_{\mathrm{u} z i}=0, \\
F_{\mathrm{u} y i}=m e\left[\left(\Omega+\dot{\theta}_{x i}\right)^{2} \cos \left(\Omega t+\theta_{x i}+\beta\right)-\ddot{\theta}_{x i} \sin \left(\Omega t+\theta_{x i}+\beta\right)\right], \\
F_{\mathrm{u} z i}=m e\left[\left(\Omega+\dot{\theta}_{x i}\right)^{2} \sin \left(\Omega t+\theta_{x i}+\beta\right)+\ddot{\theta}_{x i} \cos \left(\Omega t+\theta_{x i}+\beta\right)\right], \\
M_{\mathrm{u} x i}=m e\left[\ddot{y} \sin \left(\Omega t+\theta_{x i}+\beta\right)-(\ddot{z}+g) \cos \left(\Omega t+\theta_{x i}+\beta\right)\right],
\end{array}\right.
$$




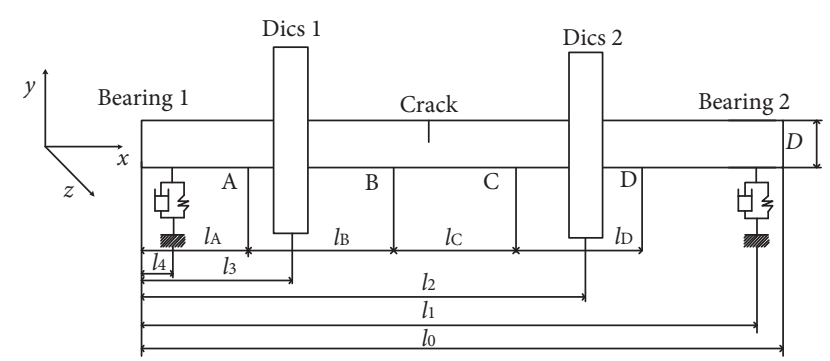

FIgure 1: The two-disc rotor-bearing system with a breathing crack.

TABle 1: Parameters of the cracked rotor.

\begin{tabular}{lc}
\hline Parameters & Value (units) \\
\hline Shaft length $\left(l_{0}\right)$ & $0.6 \mathrm{~m}$ \\
Shaft diameter $(D)$ & $0.01 \mathrm{~m}$ \\
Position of bearing $1\left(l_{4}\right)$ & $0.015 \mathrm{~m}$ \\
Position of bearing $2\left(l_{2}\right)$ & $0.575 \mathrm{~m}$ \\
Bearing stiffness & $9.6 \times 10^{5} \mathrm{~N} / \mathrm{m}$ \\
Bearing damping & $500 \mathrm{Ns} / \mathrm{m}$ \\
Position of disc 1 $\left(l_{3}\right)$ & $0.095 \mathrm{~m}$ \\
Position of disc 2 $\left(l_{2}\right)$ & $0.505 \mathrm{~m}$ \\
Disc diameter & $0.074 \mathrm{~m}$ \\
Disc thickness & $0.025 \mathrm{~m}$ \\
Disc eccentricity $(e)$ & $2 \times 10^{-5} \mathrm{~N} / \mathrm{m}$ \\
Unbalance orientation angle & 0 \\
Density of steel & $7.8 \times 10^{3} \mathrm{~kg} / \mathrm{m}^{3}$ \\
Young's modulus & $3.11 \times 10^{11} \mathrm{~Pa}$ \\
Poisson's ratio & 0.3 \\
Gravitational acceleration & $9.8 \mathrm{~m} / \mathrm{s}^{2}$ \\
Rayleigh damping coefficient $(a)$ & 0.6842 \\
Rayleigh damping coefficient $(b)$ & $2.8012 \times 10^{-5}$ \\
First critical speed & $2520 \mathrm{r} / \mathrm{min}$ \\
Rotating speed & $840 \mathrm{r} / \mathrm{min}$ \\
Measuring point $\left(l_{\mathrm{A}}\right)$ & $0.145 \mathrm{~m}$ \\
Measuring point $\left(l_{\mathrm{B}}\right)$ & $0.245 \mathrm{~m}$ \\
Measuring point $\left(l_{\mathrm{C}}\right)$ & $0.345 \mathrm{~m}$ \\
Measuring point $\left(l_{\mathrm{D}}\right)$ & $0.445 \mathrm{~m}$ \\
\hline
\end{tabular}

where $\theta_{x}(t)$ is the torsional angle, $\beta$ is the unbalance orientation angle of the disc, and $e$ is the disc eccentricity.

2.2. Model of the Shaft Element with Breathing Crack. Figure 2(a) shows a cracked shaft element of length $L$ and radius $R, a$ is the crack depth, $2 b$ is the crack width, $P_{1}-P_{12}$ are resultant forces acted upon the 12 nodes, $x-y-z$ is the global coordinate system, and $x^{\prime}-y^{\prime}-z^{\prime}$ is the local coordinate system. $x_{\mathrm{L}}$ is the distance between the center of the crack and the left end of the element, and $\theta$ is the crack angle between the cross section and the shaft centerline. The most probable angle is $45^{\circ}$ for a slant crack and $90^{\circ}$ for a transverse crack in practical engineering $[25,26,34]$, and so the crack angles studied in this paper are $45^{\circ}$ and $90^{\circ}$.

The flexibility matrix $\mathbf{G}^{0}$ of the uncracked element and the additional flexibility matrix $\mathbf{G}^{\mathrm{c}}$ of the cracked element can be derived based on SERR theory [4], and the detailed expressions can be obtained from [24].
$\mathbf{G}_{\mathrm{ce}}$ is the total flexibility matrix of the crack element, given by

$$
\mathrm{G}_{\mathrm{ce}}=\mathbf{G}^{0}+\mathbf{G}^{\mathrm{c}} \text {. }
$$

The stiffness matrix of the cracked element $\mathbf{K}_{\mathrm{ce}}$ and uncracked element $\mathbf{K}_{\text {uce }}$ can be represented as

$$
\begin{aligned}
\mathbf{K}_{\mathrm{ce}} & =\mathbf{T}\left(\mathbf{G}_{\mathrm{ce}}\right)^{-1} \mathbf{T}^{T}, \\
\mathbf{K}_{\mathrm{uce}} & =\mathbf{T}\left(\mathbf{G}^{0}\right)^{-1} \mathbf{T}^{T},
\end{aligned}
$$

where $\mathbf{T}$ is the transformation matrix written as

$$
\mathbf{T}^{T}=\left[\begin{array}{cccccccccccc}
1 & 0 & 0 & 0 & 0 & 0 & -1 & 0 & 0 & 0 & 0 & 0 \\
0 & 1 & 0 & 0 & 0 & 0 & 0 & -1 & 0 & 0 & 0 & l \\
0 & 0 & 1 & 0 & 0 & 0 & 0 & 0 & -1 & 0 & -l & 0 \\
0 & 0 & 0 & 1 & 0 & 0 & 0 & 0 & 0 & -1 & 0 & 0 \\
0 & 0 & 0 & 0 & 1 & 0 & 0 & 0 & 0 & 0 & -1 & 0 \\
0 & 0 & 0 & 0 & 0 & 1 & 0 & 0 & 0 & 0 & 0 & -1
\end{array}\right] .
$$

So as to simulate the breathing behavior of the crack, the stiffness of the crack element is calculated based on the classical theory of crack closure line (CCL) [24], which is a hypothetical line separating the closed and open parts of the crack (Figure 2). The crack front is subdivided into $m$ parts, the opening mode stress intensity factor $K_{\mathrm{I}}$ is calculated by Equation (7), and a positive $K_{\mathrm{I}}$ corresponds to the open crack state and a negative $K_{\mathrm{I}}$ to the closed state. Thus, the location of the CCL is determined, and the stiffness matrix of the crack element can be obtained as

$$
K_{\mathrm{I}}=\sum_{i=1}^{6} K_{\mathrm{I} i}
$$

The Newmark method [35] is utilized to solve the equations numerically, setting the Newmark parameters $\delta=0.5$ and $\alpha_{n}=0.25$ to ensure numerical stability.

2.3. Superharmonic Components Analysis of the Cracked Rotor System. The superharmonic components in subcritical speed region can be used as index to detect the cracks in the rotorbearing systems $[36,37]$. The vertical vibration response of the rotor-bearing system is collected at four measuring points (illustrated as A, B, C, and D in Figure 1), and the rotating speed is $1 / 3$ of the first critical speed $(840 \mathrm{r} / \mathrm{min})$ of the system. The $1 \mathrm{X}, 2 \mathrm{X}$, and $3 \mathrm{X}$ superharmonic components amplitudes of the vibration response at the measuring point A are obtained through fast Fourier transform (FFT).

Figure 3 depicts the amplitude curves of superharmonic components of the vertical vibration response with different crack depths as the crack is located at the 21st element of the shaft. It shows that the $2 \mathrm{X}$ amplitude increases with increasing crack depths, the $1 \mathrm{X}$ and $2 \mathrm{X}$ amplitudes resulted from transverse crack are greater than those from slant crack, and the $1 \mathrm{X}, 2 \mathrm{X}$, and $3 \mathrm{X}$ amplitudes by transverse crack are close to those by slant crack as the crack depth is small.

Figure 4 depicts the amplitudes curves of superharmonic components of the vertical vibration response 


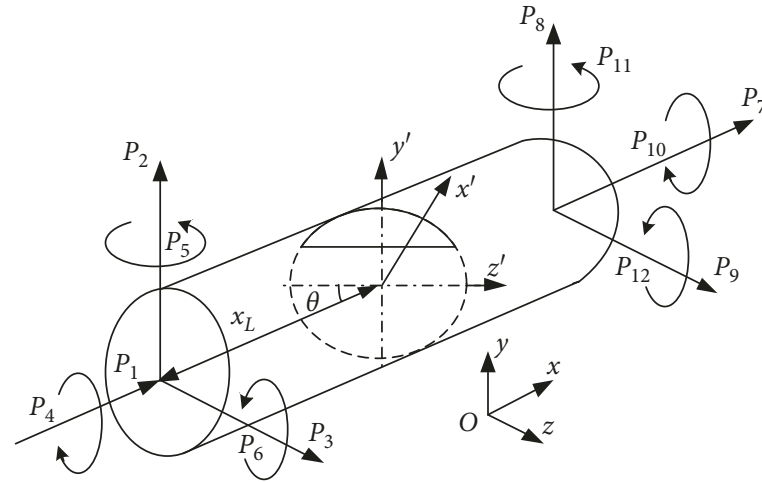

(a)

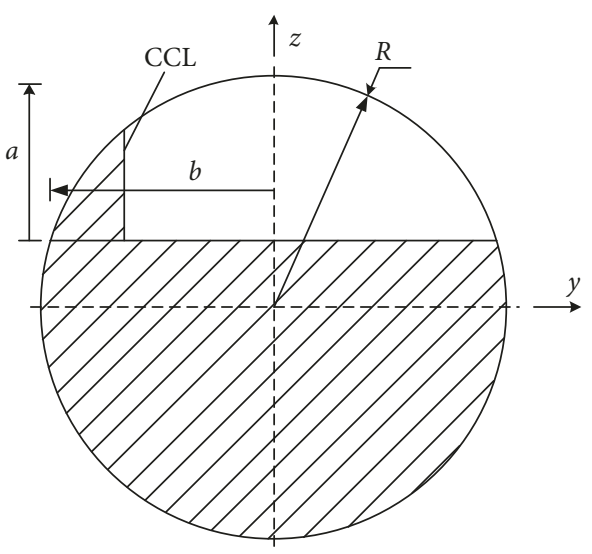

(b)

FIGURE 2: Schematic diagram of cracked shaft element. (a) Cracked shaft element. (b) Crack cross section.

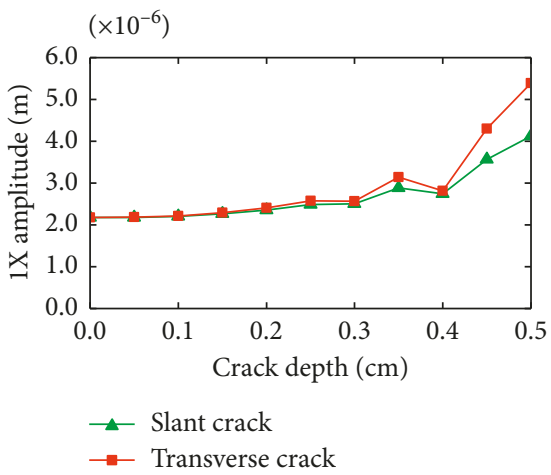

(a)

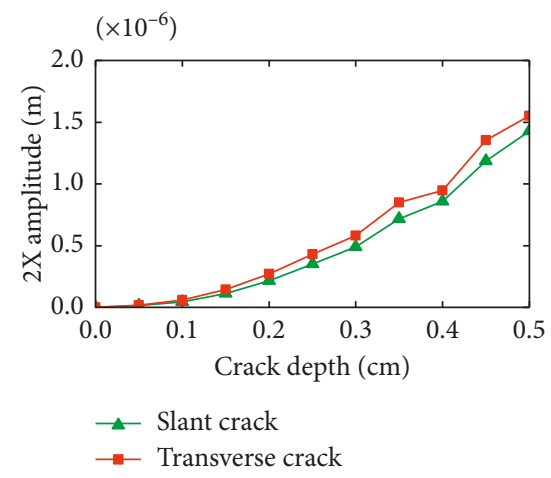

(b)

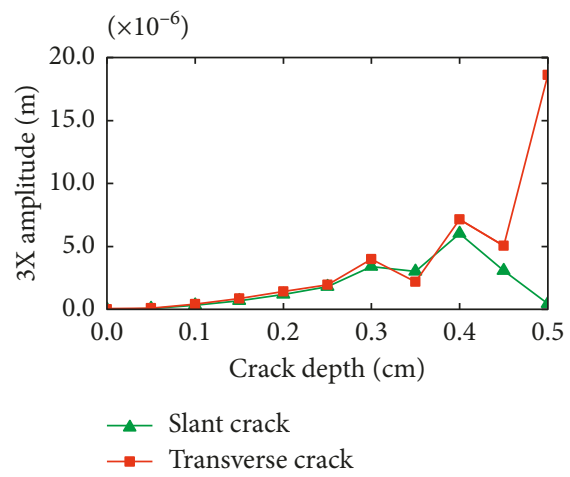

(c)

FIgURE 3: The amplitude curves of superharmonic components with different crack depths. (a) $1 \mathrm{X}$ amplitude; (b) $2 \mathrm{X}$ amplitude; (c) $3 \mathrm{X}$ amplitude.

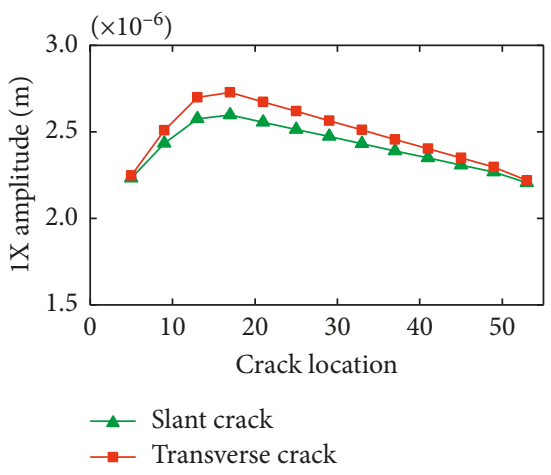

(a)

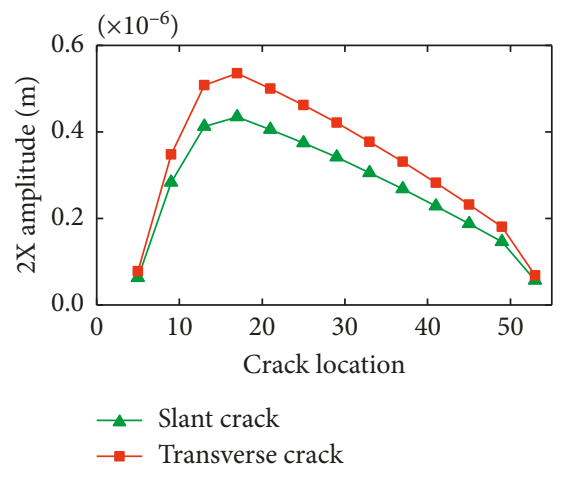

(b)

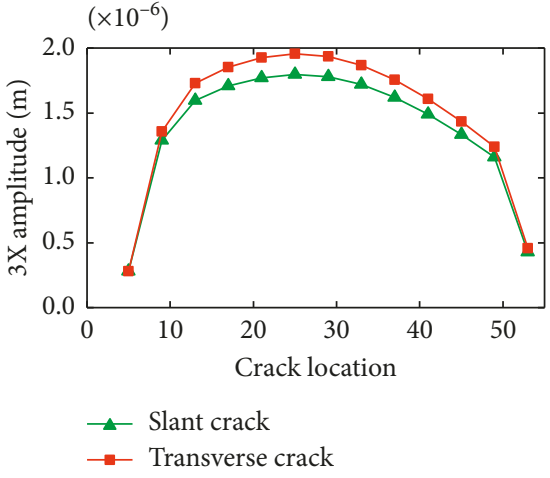

(c)

FIgURe 4: The superharmonic components amplitudes with different crack locations. (a) 1X amplitude; (b) 2X amplitude; (c) 3X amplitude.

with different crack location as the crack depth is $0.25 \mathrm{~cm}$. It shows that the $1 \mathrm{X}, 2 \mathrm{X}$, and $3 \mathrm{X}$ amplitudes generated by transverse crack are greater than those by slant crack and the $1 \mathrm{X}, 2 \mathrm{X}$, and $3 \mathrm{X}$ amplitudes generated by transverse crack are close to those by slant crack as the crack is near the bearing.
As the $1 \mathrm{X}$ and $2 \mathrm{X}$ amplitudes of the vertical vibration response for the cracked rotor-bearing system are more sensitive to crack parameters, then the $1 \mathrm{X}$ and $2 \mathrm{X}$ amplitudes are selected as the index vectors for crack identification, and the superharmonic features of the four measuring points are utilized to avoid the multisolution 
problem in the process of crack parameters identification.

\section{Construction of the Kriging Surrogate Model}

The problem of crack parameters identification can be transformed to an optimization problem. Using optimization methods to estimate the optimal parameters via minimizing the objective function relating to output deviations such as dynamical response and modal parameters [38, 39]. However, the optimization process requires a large number of iterative steps, and each iterative step needs to repeat calculation of complex finite element models, making the problem very complicated. Thus, it is necessary to establish an uncomplicated relationship between the crack parameters and the superharmonic features for crack identification.

The Kriging surrogate model provides explicit functions to represent the relationships between inputs and outputs of a linear or nonlinear system [39], which is a statistics-based interpolation method and is not affected by random error $[31,32]$. Construction of the Kriging model requires small amount of samples to obtain high estimation accuracy, significantly reducing calculation time.

Given initial crack parameters samples and the corresponding $1 \mathrm{X}$ and $2 \mathrm{X}$ amplitudes are

$$
\mathbf{X}=\left[\begin{array}{c}
\mathbf{x}_{1} \\
\mathbf{x}_{2} \\
\mathbf{x}_{3} \\
\vdots \\
\mathbf{x}_{n}
\end{array}\right]=\left[\begin{array}{ccc}
l_{1} & d_{1} & \beta_{1} \\
l_{2} & d_{2} & \beta_{2} \\
l_{2} & d_{2} & \beta_{2} \\
\vdots & \vdots & \vdots \\
l_{n} & d_{n} & \beta_{n}
\end{array}\right]
$$

where $\mathbf{x}_{i}=\left\{l_{i}, d_{i}, \theta_{i}\right\}$ is the $i$ th component of sampling crack parameters ( $l_{i}$ is the crack position, $d_{i}$ is the crack depth, and $\theta_{i}$ is the crack angle), represented as a three-dimensional variable vector, $l_{*} \in[5,55], l_{*} \in Z, d_{*} \in[0.05,0.5]$, and $\theta_{*} \in\{45,90\}$.

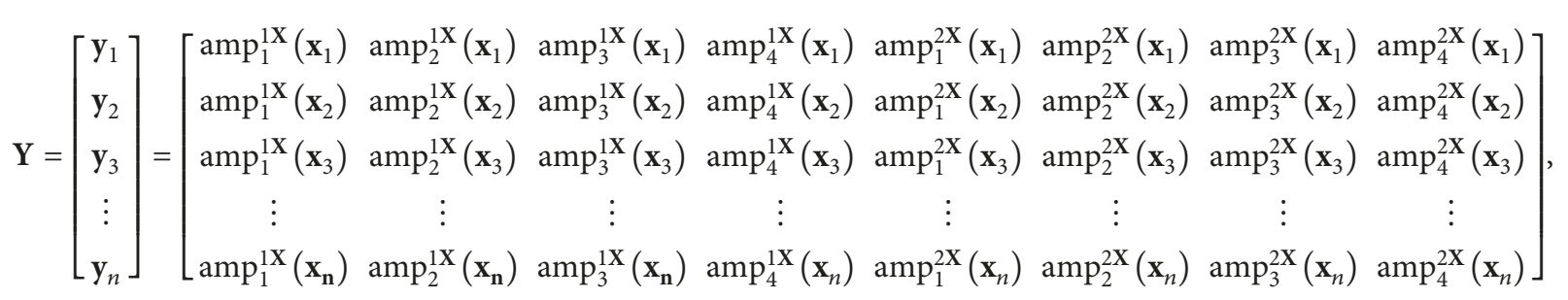

where $\mathbf{y}_{i}$ is the $i$ th set of the output $\mathbf{Y}$ vector, $\operatorname{amp}_{n}^{m \mathbf{X}}\left(\mathbf{x}_{i}\right)$ is the superharmonic components amplitudes at the $n$th measurement point, and $n=1,2,3,4$ and $m=1,2$.

And their relationship can be written as

$$
y_{l}\left(\mathbf{x}_{i}\right)=\mathbf{f}\left(\mathbf{x}_{i}\right)^{T} \boldsymbol{\beta}+\varepsilon_{l}\left(\mathbf{x}_{i}\right), \quad i=1,2, \ldots, n, l=1,2, \ldots, q,
$$

where $\mathbf{f}\left(\mathbf{x}_{i}\right)$ is a vector of a linear combination of selected functions, $\boldsymbol{\beta}$ is the matrix of regression coefficients, $\varepsilon_{l}\left(\mathbf{x}_{i}\right)$ is the stochastic process with a variance of $\sigma_{l}^{2}$ and a mean of zero, and $q$ is the dimension of the $\mathbf{Y}$ vector. The covariance matrix is expressed by

$$
\begin{aligned}
\operatorname{Cov}\left[\varepsilon_{l}\left(\mathbf{x}_{i}\right), \varepsilon_{l}\left(\mathbf{x}_{j}\right)\right]=\sigma_{l}^{2} \mathbf{R}\left(\theta, \mathbf{x}_{i}, \mathbf{x}_{j}\right), \quad i, j & =1,2, \ldots, n, \\
l & =1,2, \ldots, q .
\end{aligned}
$$

$\mathbf{R}$ is the Gauss correlation function matrix and $\theta$ is the correlation parameter, given by

$$
\mathbf{R}_{i, j}\left(\theta, \mathbf{x}_{i}, \mathbf{x}_{j}\right)=\exp \left(-\theta\left\|\mathbf{x}_{i}-\mathbf{x}_{j}\right\|\right), \quad i, j=1,2, \ldots, n .
$$

When existing an untested crack parameter $x^{*}$, the corresponding superharmonic component amplitudes can be estimated as the linear predictor, which is shown as

$$
\hat{y}_{l}^{*}\left(x^{*}\right)=\mathbf{c}^{\mathrm{T}} \mathbf{y}_{l}, \quad l=1,2, \ldots, q,
$$

where $\mathbf{c}$ is a $n \times 1$ coefficient vector and $\mathbf{y}_{l}$ is the $l$ th column of the matrix $\mathbf{Y}$.

The correlation vector $\mathbf{r}(\mathbf{x})$ can be written as

$$
\mathbf{r}(\mathbf{x})=\left[R_{i, j}\left(\theta, \mathbf{x}_{1}, \mathbf{x}^{*}\right), R_{i, j}\left(\theta, \mathbf{x}_{2}, \mathbf{x}^{*}\right), \ldots, R_{i, j}\left(\theta, \mathbf{x}_{n}, \mathbf{x}^{*}\right)\right]^{T},
$$

where $\mathbf{x}_{i}$ is the initial crack samples and $\mathbf{x}^{*}$ is the new sample.

The predicted error is

$$
\begin{aligned}
\hat{y}_{l}^{*}\left(\mathbf{x}^{*}\right)-y_{l}\left(\mathbf{x}^{*}\right)= & \mathbf{c}^{T} \mathbf{y}_{l}-y_{l}\left(\mathbf{x}^{*}\right)=\mathbf{c}^{T} \mathbf{Z}_{l}-z_{l}\left(\mathbf{x}^{*}\right) \\
& +\left(\mathbf{F}^{T} \mathbf{c}-\mathbf{f}\left(\mathbf{x}^{*}\right)\right)^{T} \boldsymbol{\beta}_{l},
\end{aligned}
$$

in which

$$
\begin{aligned}
\mathbf{Z}_{l} & =\left[z_{1}\left(\mathbf{x}_{1}\right), z_{1}\left(\mathbf{x}_{2}\right), \ldots, z_{1}\left(\mathbf{x}_{n}\right)\right], \\
\mathbf{F} & =\left[\begin{array}{ccc}
f_{1}\left(\mathbf{x}_{1}\right) & \cdots & f_{p}\left(\mathbf{x}_{1}\right) \\
\vdots & \ddots & \vdots \\
f_{1}\left(\mathbf{x}_{n}\right) & \cdots & f_{p}\left(\mathbf{x}_{n}\right)
\end{array}\right] .
\end{aligned}
$$

To keep the predictor unbiased, it is required that

$$
\mathbf{F}^{T} \mathbf{c}-\mathbf{f}\left(\mathbf{x}^{*}\right)=0 .
$$

Under this condition, the mean squared error of Equation (13) is 


$$
\begin{aligned}
\varphi_{l}\left(\mathbf{x}^{*}\right) & =E\left[\left(y_{l}^{*}\left(\mathbf{x}^{*}\right)-y_{l}\left(\mathbf{x}^{*}\right)\right)^{2}\right]=E\left[\left(\mathbf{c}^{T} z_{l}-z_{l}\left(\mathbf{x}^{*}\right)\right)^{2}\right] \\
& =\sigma_{l}^{2}\left(1+\mathbf{c}^{T} \mathbf{R} \mathbf{c}-2 \mathbf{c}^{T} \mathbf{r}\right) .
\end{aligned}
$$

The Lagrangian function for the problem of minimizing the mean squared error with the constraint of Equation (17) is

$$
L(\mathbf{c}, \boldsymbol{\lambda})=\sigma_{l}^{2}\left(1+\mathbf{c}^{T} \mathbf{R} \mathbf{c}-2 \mathbf{c}^{T} \mathbf{r}\right)-\boldsymbol{\lambda}^{T}\left(\mathbf{F}^{T} \mathbf{c}-\mathbf{f}\left(\mathbf{x}^{*}\right)\right) .
$$

The gradient of Equation (19) with respect to $c$ is

$$
L_{\mathrm{c}}^{\prime}(\mathbf{c}, \boldsymbol{\lambda})=2 \sigma_{l}^{2}(\mathbf{R} \mathbf{c}-\mathbf{r})-\mathbf{F} \boldsymbol{\lambda} .
$$

According to the first order necessary conditions for optimality

$$
\mathbf{c}=\mathbf{R}^{-1}\left(\mathbf{r}-\mathbf{F}\left(\mathbf{F}^{T} \mathbf{R}^{-1} \mathbf{F}\right)^{-1}\left(\mathbf{F}^{T} \mathbf{R}^{-1} \mathbf{r}-\mathbf{f}\left(\mathbf{x}^{*}\right)\right)\right) .
$$
gives

Substituting the above equation into Equation (10)

$$
y_{l}^{*}\left(\mathbf{x}^{*}\right)=\mathbf{R}^{-T}\left(\mathbf{r}-\mathbf{F}\left(\mathbf{F}^{T} \mathbf{R}^{-1} \mathbf{F}\right)^{-1}\left(\mathbf{F}^{T} \mathbf{R}^{-1} \mathbf{r}-\mathbf{f}\left(\mathbf{x}^{*}\right)\right)\right)^{T} \mathbf{y}_{l} .
$$

Hence, the relation between crack parameters and the corresponding $1 \mathrm{X}$ and $2 \mathrm{X}$ amplitudes values has been deduced.

After the Kriging surrogate model is established, the squared multiple correlations (SMC) and the empirical integrated squared error (EISE) criterion [40] can be used to evaluate the preciseness of the Kriging surrogate model.

$$
\begin{aligned}
\mathrm{SC} & =1-\frac{\sum_{j=1}^{q}\left[\hat{y}_{l}-y_{l}\right]^{2}}{\sum_{j=1}^{q}\left[y_{l}-\hat{y}\right]^{2}}, \\
\mathrm{EISE} & =\frac{1}{q} \sum_{l=1}^{q}\left[\hat{y}_{l}-y_{l}\right]^{2},
\end{aligned}
$$

where $\hat{y}_{l}$ is the $l$ th set of the $\mathbf{Y}$ vector of the Kriging surrogate model, $y_{l}$ is the $l$ th component of the superharmonic component amplitudes calculated by finite element analysis, $\hat{y}$ is the mean of the true values, and $q$ is the length of the vector $\hat{y}_{l}$. This paper adopts the multipoint adding strategy to update the Kriging surrogate model if the predicted superharmonic components amplitudes cannot meet SC and EISE [41].

\section{Crack Parameters Identification Based on an Improved NSGA-III}

After the Kriging surrogate model between crack parameters and the superharmonic components amplitudes is established, crack parameters identification problem is transformed into a multiobjective optimization problem, which can be stated as follows:

$$
\text { find } x^{*}=\left\{l_{*}, d_{*}, \theta_{*}\right\} \text {, }
$$

$$
\min \left\{\begin{array}{l}
\text { Object } 1=\left|\operatorname{amp}_{1}^{1 \mathbf{X}}\left(x^{*}\right)-\operatorname{amp}_{1}^{1 \mathbf{X}}\left(x^{\text {Target }}\right)\right|, \\
\text { Object } 2=\left|\operatorname{amp}_{2}^{1 \mathbf{X}}\left(x^{*}\right)-\operatorname{amp}_{2}^{1 \mathbf{X}}\left(x^{\text {Target }}\right)\right|, \\
\text { Object } 3=\left|\operatorname{amp}_{3}^{1 \mathbf{X}}\left(x^{*}\right)-\operatorname{amp}_{3}^{1 \mathbf{X}}\left(x^{\text {Target }}\right)\right|, \\
\text { Object } 4=\left|\operatorname{amp}_{4}^{1 \mathbf{X}}\left(x^{*}\right)-\operatorname{amp}_{4}^{1 \mathbf{X}}\left(x^{\text {Target }}\right)\right|, \\
\text { Object } 5=\left|\operatorname{amp}_{1}^{2 \mathbf{X}}\left(x^{*}\right)-\operatorname{amp}_{1}^{2 \mathbf{X}}\left(x^{\text {Target }}\right)\right|, \\
\text { Object } 6=\left|\operatorname{amp}_{2}^{2 \mathbf{X}}\left(x^{*}\right)-\operatorname{amp}_{2}^{2 \mathbf{X}}\left(x^{\text {Target }}\right)\right|, \\
\text { Object } 7=\left|\operatorname{amp}_{3}^{2 \mathbf{X}}\left(x^{*}\right)-\operatorname{amp}_{3}^{2 \mathbf{X}}\left(x^{\text {Target }}\right)\right|, \\
\text { Object } 8=\left|\operatorname{amp}_{4}^{2 \mathbf{X}}\left(x^{*}\right)-\operatorname{amp}_{4}^{2 \mathbf{X}}\left(x^{\text {Target }}\right)\right|,
\end{array}\right.
$$

with

$$
\begin{aligned}
& l_{*} \in[5,55], \\
& l_{*} \in Z, \\
& d_{*} \in[0.05,0.5], \\
& \theta_{*} \in\{45,90\},
\end{aligned}
$$

where $\operatorname{amp}_{n}^{m \mathbf{X}}\left(x^{*}\right)$ and $\mathrm{amp}_{n}^{m \mathrm{X}}\left(x^{\text {Target }}\right)$ are the $m \times$ superharmonic component amplitudes at the $n$th measurement point. $\operatorname{amp}_{n}^{m \mathrm{X}}\left(x^{*}\right)$ is calculated via the Kriging surrogate model and $\mathrm{amp}_{n}^{m \mathrm{X}}\left(x^{\text {Target }}\right)$ is measured on actual cracked rotor, and $n=1,2,3,4$ and $m=1,2$.

It is a great challenge for the classical multiobjective optimization algorithms when the optimization problem involves four or more objectives. To get the global optimal solution, the NSGA-III recently proposed by Deb and Jain $[29,30]$ may be a good choice to optimize 8 objective functions at the same time. NSGA-III is an evolutionary many-objective optimization algorithm based on reference point, which can ensure the diversity of population members via adaptively updating a number of well-spread reference points.

The crack angles considered are $45^{\circ}$ or $90^{\circ}$, and the crack is located in the $l_{*}$ th element in this paper. If the NSGA-III is directly used for crack parameters identification in the iterative process, the crack parameters of the population members are mostly decimal numbers, causing crack parameters identification results to be inaccurate. In addition, the decimal crack parameters reduce the convergence rate of the objective function and increase the optimization time.

Therefore, the NSGA-III needs to be improved for crack identification of the rotor-bearing system. Preprocessing of population members is added before members' selection in every iterative process to obtain crack parameters accurately and efficiently, and the improved part of the NSGA-III is as follows.

(1) Preprocessing of crack position:

$$
l_{t}^{*}=\operatorname{Round}\left(l_{t}\right),
$$

where $l_{t}^{*}$ is the crack position obtained by preprocessing of $l_{t}$ at the $t$ th generation and Round is the rounding function. 
(2) Preprocessing of crack angle:

$$
\theta_{t}^{*}=\text { Round }\left[\frac{\left(\theta_{t}-45^{\circ}\right)}{45^{\circ}}+1\right] \times 45^{\circ},
$$

where $\theta_{t}^{*}$ is the crack angle obtained after preprocessing of $\theta_{t}$ at the $t$ th generation. The preprocessing of the crack angle can make the crack angle close to $45^{\circ}$ or $90^{\circ}$ change to $45^{\circ}$ or $90^{\circ}$.

Replace $l_{t}$ and $\theta_{t}$ with $l_{t}^{*}$ and $\theta_{t}^{*}$ to form a new population.

There are many Pareto optimal solutions by the improved NSGA-III. As it is very difficult to have a set of crack parameters that minimize all the objective function values, an index is required to select the optimal crack parameters in the Pareto optimal solutions.

By defining Mobw as the selection index of the crack parameters identification results, Mobw can be obtained by weighing each objective function value:

$$
\text { Mobw }=\sum_{i=1}^{8} \operatorname{Object}(i) \times k_{i} \text {, }
$$

where $k_{i}$ is the weight coefficient, and $k_{1}=k_{2}=k_{3}=k_{4}=$ 0.15 and $k_{5}=k_{6}=k_{7}=k_{8}=0.1$ in this paper.

The corresponding identification result of the minimum value of Mobw is taken as the final crack parameters.

\section{Numerical Investigation}

5.1. Identification Results Based on a Kriging Surrogate Model. Numerical experiments are carried out to verify the effectiveness of the method. The detailed parameters of the rotorbearing system are given in Table 1, 300 sets of samples of crack parameters are generated by Latin hypercube sampling [42], and then corresponding vertical vibration response of the rotor-bearing system assuming a 5\% random white noise is collected at four measuring points. Then, the Kriging surrogate model between crack parameters and corresponding $1 \mathrm{X}$ and $2 \mathrm{X}$ amplitudes is established.

The improved NSGA-III is employed to estimate the crack parameters found on the Kriging surrogate model by minimizing the multiobjective function values given in Equation (25), and the initial parameters of the improved NSGA-III are as follows: the population size, maximum number of iterations, crossover percentage, and mutation percentage are $150,100,0.5$, and 0.5 , respectively.

The flowchart of the method for identifying crack parameters based on the improved NSGA-III and Kriging surrogate model is shown in Figure 5.

This paper considers eight cases (Table 2) to evaluate the performance of the proposed method and selects case 1 to analyze the identification process of crack parameters for rotors in detail.

Figure 6 illustrates the mean value of objective function varies with evolutionary generations, and it shows that the mean value of objective function optimized by the improved NSGA-III has already converged in the 30th generation,

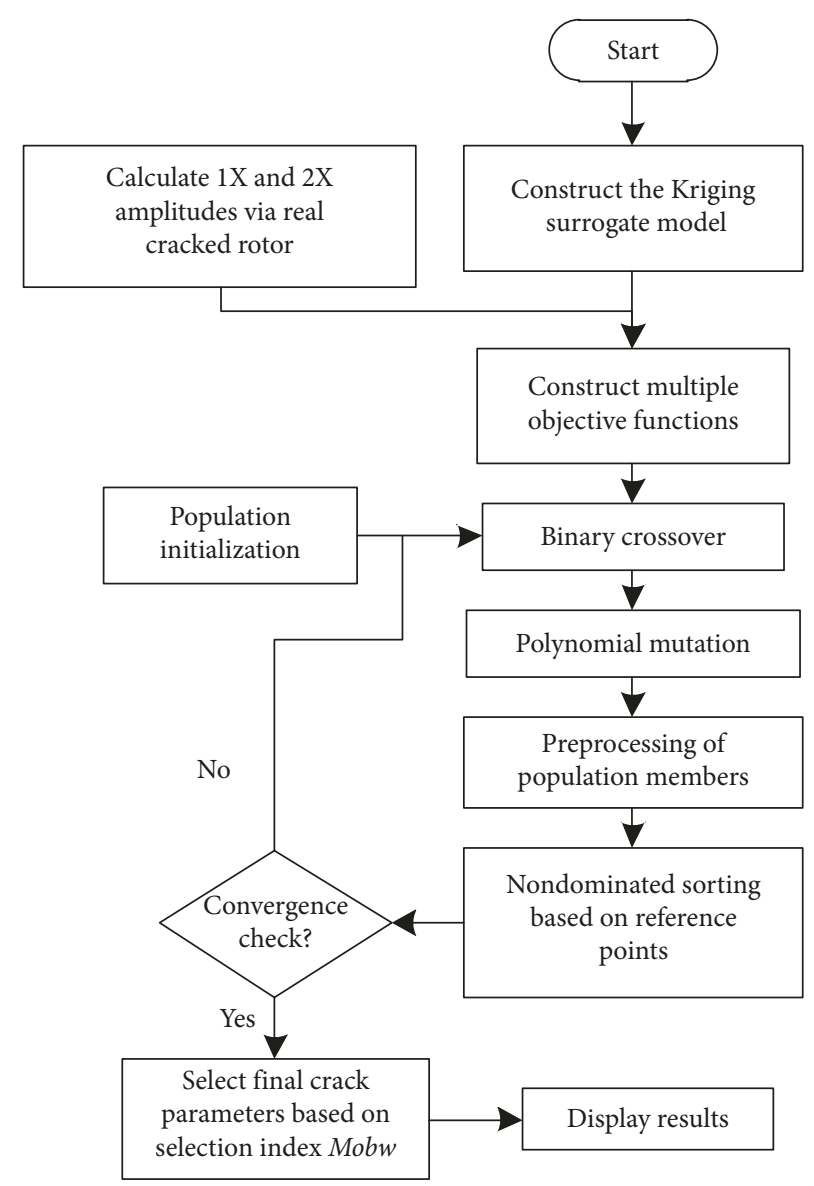

FIGURE 5: Flowchart of the method for crack parameters identification.

while the mean value of the objective function with the original NSGA-III not only has higher values but also has a slow convergence speed.

The crack parameters results identified with the improved NSGA-III are compared with results with the original NSGA-III (Figure 7), and it can be seen that the crack parameters obtained by the improved NSGA-III are closer to the actual crack parameters in Pareto optimal sets.

Figures 6 and 7 indicate that the improved NSGA-III can obtain Pareto optimal solutions accurately and efficiently.

The values of the objective function corresponding to each group of crack parameters in Pareto optimal solution are shown in Figure 8, and it is necessary to select a best set of solutions based on the index Mobw in Equation (29).

As shown in Figure 9, the selection index Mobw achieves the minimum value in the 90th population member, and the corresponding crack parameter is $\mathbf{x}_{i}^{*}=\{20,0.375066,90\}$. Compared with other crack parameters in Pareto optimal solutions, the 90th set of parameters is closer to the actual values (marked as blue circle in Figure 7), which indicates that it is reasonable to select the optimal crack parameters by the index Mobw.

The identified crack parameters are listed in Table 2, and it is worth noting that results are very accurate except for case 3 , as the crack depth and crack position in case 3 are 
TABle 2: Crack parameters identification results using 300 sets of samples.

\begin{tabular}{|c|c|c|c|c|c|c|c|c|c|}
\hline \multirow[b]{2}{*}{ Case } & \multicolumn{3}{|c|}{ Actual crack parameters } & \multicolumn{3}{|c|}{ Predicted crack parameters } & \multicolumn{3}{|c|}{ Percentage error } \\
\hline & $\begin{array}{c}\text { Position, } l \\
\text { (element) }\end{array}$ & Depth, $D(\mathrm{~cm})$ & $\begin{array}{l}\text { Angle, } \theta \\
\text { (degrees) }\end{array}$ & $\begin{array}{c}\text { Position, } l^{*} \\
\text { (element) }\end{array}$ & Depth, $D^{*}(\mathrm{~cm})$ & $\begin{array}{l}\text { Angle, } \theta^{*} \\
\text { (degrees) }\end{array}$ & Error (\%) & Error (\%) & Error (\%) \\
\hline 1 & 20 & 0.375 & 90 & 20 & 0.37507 & 90 & 0.00 & 0.01 & 0.00 \\
\hline 2 & 31 & 0.25 & 45 & 31 & 0.24988 & 45 & 0.00 & 0.05 & 0.00 \\
\hline 3 & 50 & 0.1 & 45 & 49 & 0.15224 & 45 & 2.00 & 52.4 & 0.00 \\
\hline 4 & 25 & 0.125 & 45 & 25 & 0.12145 & 45 & 0.00 & 2.84 & 0.00 \\
\hline 5 & 21 & 0.225 & 90 & 21 & 0.20255 & 90 & 0.00 & 9.98 & 0.00 \\
\hline 6 & 19 & 0.45 & 90 & 19 & 0.44813 & 90 & 0.00 & 0.42 & 0.00 \\
\hline 7 & 49 & 0.225 & 45 & 49 & 0.22714 & 45 & 0.00 & 0.95 & 0.00 \\
\hline 8 & 17 & 0.3 & 45 & 17 & 0.29411 & 45 & 0.00 & 1.96 & 0.00 \\
\hline
\end{tabular}

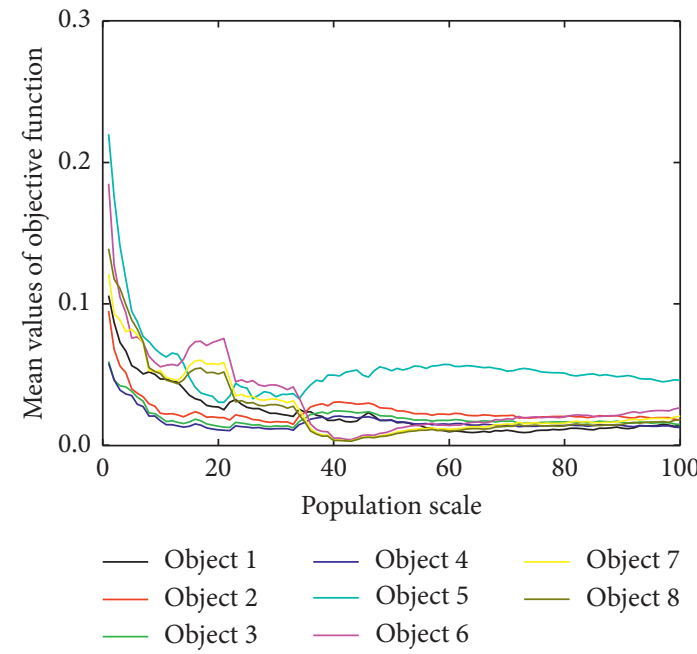

(a)

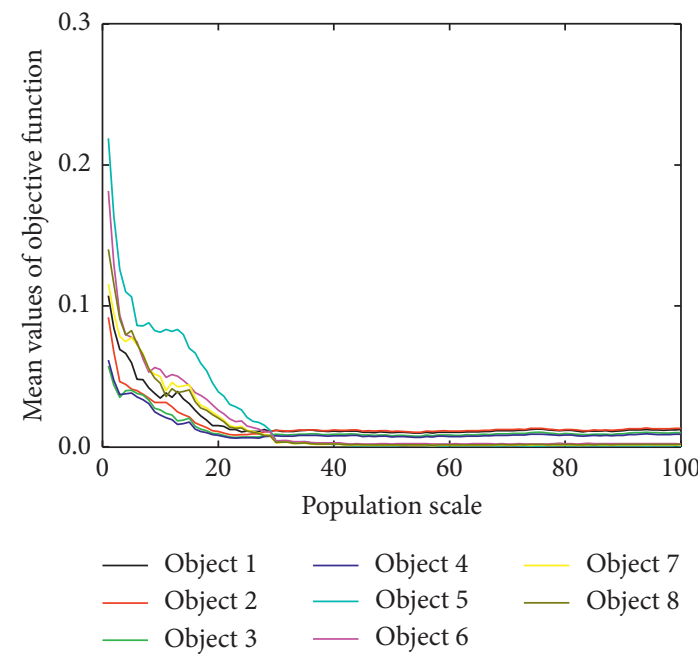

(b)

FIGURE 6: The mean value of objective function varies with evolutionary generations obtained by (a) original NSGA-III and (b) improved NSGA-III.

near the boundary (crack location is close to the 55th element and crack depth is close to $0.1 \mathrm{~cm}$ ), so the $1 \mathrm{X}$ and $2 \mathrm{X}$ amplitudes predicted by the Kriging surrogate model are less accurate. The accuracy of crack parameter identification results is improved by increasing the number of samples in the boundary area.

5.2. Comparison with the Results by Artificial Neural Networks. Artificial neural network (ANN) models are widely used in engineering for regression and classification, which have been proved to be effective in identifying the crack location and depth using modal parameters of static rotors $[9,10]$. In order to explain the accuracy and efficiency of the proposed method in identifying the crack parameters, ANN is used to construct the relationship between superharmonic components amplitudes and crack parameters of a rotating rotor-bearing system.

The configuration of ANN used in this paper is backpropagation algorithm (BPA), and the input and target output for training are expressed, respectively, as $\mathbf{P}=\left[\begin{array}{llll}\mathbf{P}_{1} & \mathbf{P}_{2} & \cdots & \mathbf{P}_{n}\end{array}\right]$ and $\mathbf{T}=\left[\begin{array}{llll}\mathbf{T}_{1} & \mathbf{T}_{2} & \cdots & \mathbf{T}_{n}\end{array}\right]$, where
$\mathbf{P}=\mathbf{Y}^{T}, \mathbf{Y}$ is the superharmonic components matrix in Equation (9) and $\mathrm{T}=X^{T}, X$ is the crack parameters matrix in Equation (10). A single hidden layer containing 20 neurons is designed for training process, and the training progress of ANN uses Levenberg-Marquardt backpropagation algorithm.

The 300 sets of samples same as that in Section 5.1 are used to construct the neural network, assuming the 5\% random white noise. Table 3 shows crack parameters identified by ANN, and it is imprecise compared with identified results obtained by the proposed method (Table 2) in this paper.

In addition, the crack parameters identification results obtained by the training neural network with 600 sets of samples are shown in Table 4, and it can be found that increasing the samples number trained by neural network can improve the identification accuracy of crack parameters.

However, increasing the number of samples requires more time for finite element calculation, and identified results are still imprecise compared with that obtained by the proposed method (Table 2) in this paper. 


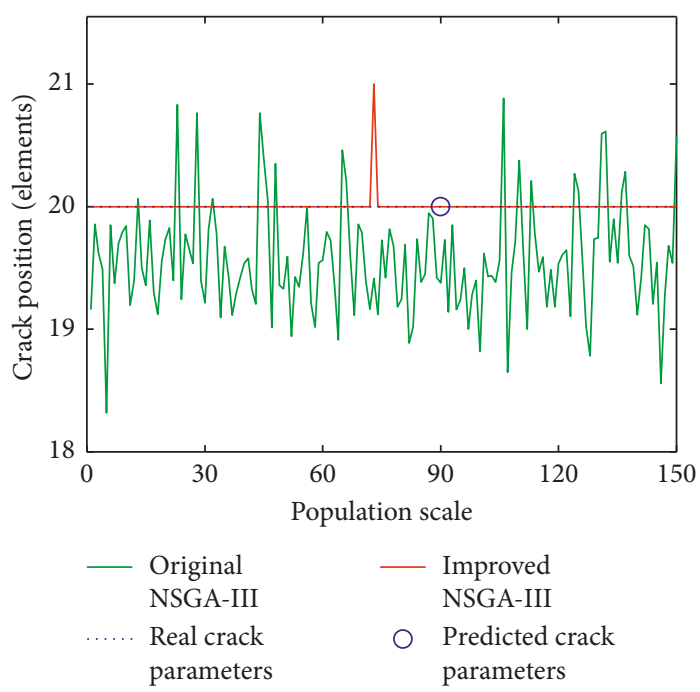

(a)

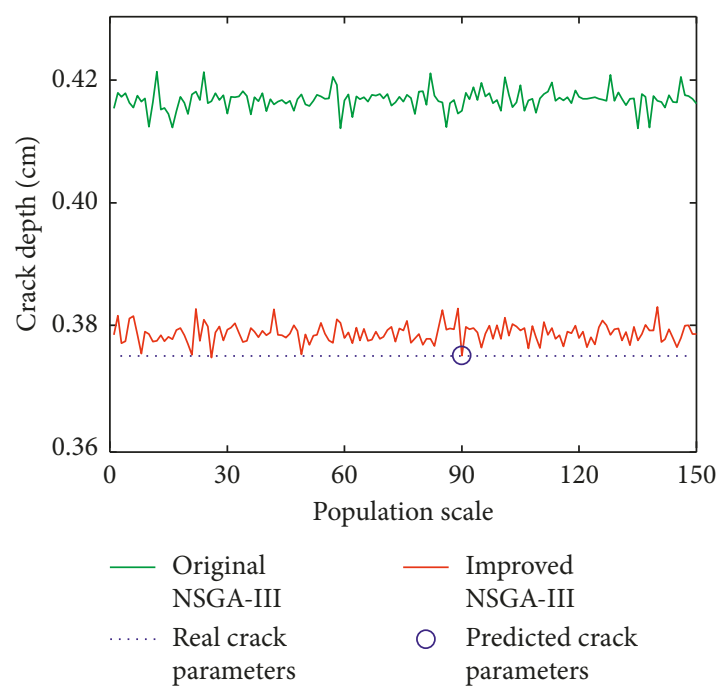

(b)

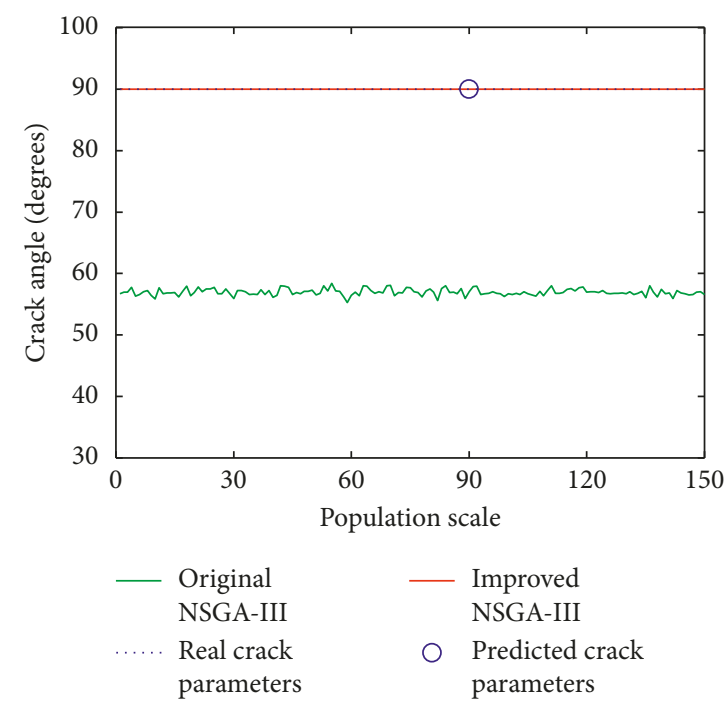

(c)

Figure 7: Comparison of Pareto optimal sets obtained by two methods: (a) crack position; (b) crack depth; (c) crack angle.

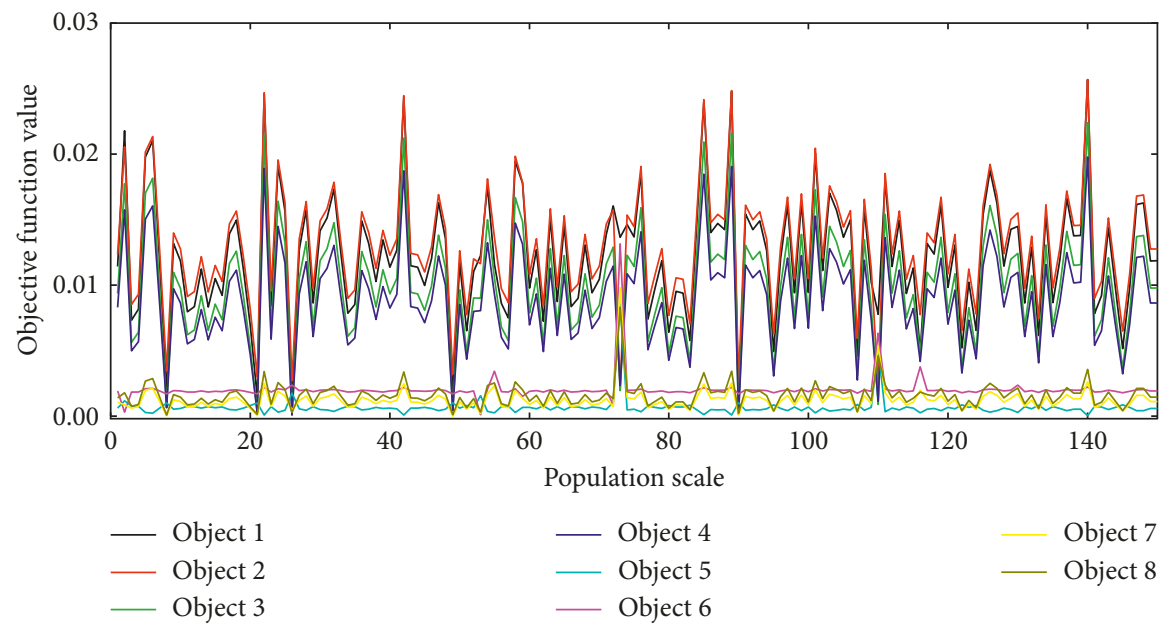

FIGURE 8: The objective function values corresponding to crack parameters in Pareto optimal solution. 


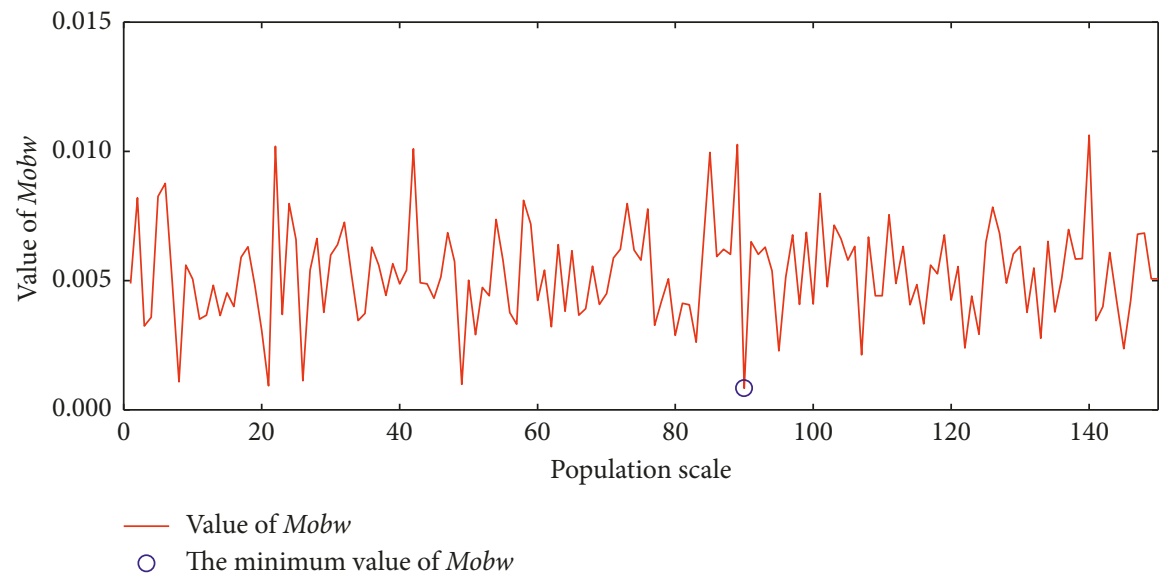

Figure 9: Index Mobw selection of crack identification results.

TABLE 3: Crack parameters identification results by ANN using 300 sets of samples.

\begin{tabular}{|c|c|c|c|c|c|c|c|c|c|}
\hline \multirow[b]{2}{*}{ Case } & \multicolumn{3}{|c|}{ Actual crack parameters } & \multicolumn{3}{|c|}{ Predicted crack parameters by ANN } & \multicolumn{3}{|c|}{ Percentage error } \\
\hline & $\begin{array}{c}\text { Position, } l \\
\text { (element) }\end{array}$ & Depth, $D(\mathrm{~cm})$ & $\begin{array}{l}\text { Angle, } \theta \\
\text { (degrees) }\end{array}$ & $\begin{array}{l}\text { Position, } l^{*} \\
\text { (element) }\end{array}$ & Depth, $D^{*}(\mathrm{~cm})$ & $\begin{array}{l}\text { Angle, } \theta^{*} \\
\text { (degrees) }\end{array}$ & Error (\%) & Error $(\%)$ & Error $(\%)$ \\
\hline 1 & 20 & 0.375 & 90 & 20 & 0.39386 & 90 & 0.00 & 5.03 & 0.00 \\
\hline 2 & 31 & 0.25 & 45 & 31 & 0.25569 & 45 & 0.00 & 2.28 & 0.00 \\
\hline 3 & 50 & 0.1 & 45 & 48 & 0.10314 & 45 & 4.00 & 3.14 & 0.00 \\
\hline 4 & 25 & 0.125 & 45 & 28 & 0.11122 & 45 & 12.00 & 11.02 & 0.00 \\
\hline 5 & 21 & 0.225 & 90 & 20 & 0.22909 & 45 & 4.76 & 1.81 & 50.00 \\
\hline 6 & 19 & 0.45 & 90 & 23 & 0.49150 & 90 & 21.01 & 9.22 & 0.00 \\
\hline 7 & 49 & 0.225 & 45 & 49 & 0.22645 & 45 & 0.00 & 0.64 & 0.00 \\
\hline 8 & 17 & 0.3 & 45 & 17 & 0.27013 & 45 & 0.00 & 9.96 & 0.00 \\
\hline
\end{tabular}

TABLE 4: Crack parameters identification results by ANN using 600 sets of samples.

\begin{tabular}{|c|c|c|c|c|c|c|c|c|c|}
\hline \multirow[b]{2}{*}{ Case } & \multicolumn{3}{|c|}{ Actual crack parameters } & \multicolumn{3}{|c|}{ Predicted crack parameters by ANN } & \multicolumn{3}{|c|}{ Percentage error } \\
\hline & $\begin{array}{c}\text { Position, } l \\
\text { (element) }\end{array}$ & Depth, $D(\mathrm{~cm})$ & $\begin{array}{l}\text { Angle, } \theta \\
\text { (degrees) }\end{array}$ & $\begin{array}{r}\text { Position, } l^{*} \\
\text { (element) }\end{array}$ & Depth, $D^{*}(\mathrm{~cm})$ & $\begin{array}{l}\text { Angle, } \theta^{*} \\
\text { (degrees) }\end{array}$ & Error (\%) & Error (\%) & Error $(\%)$ \\
\hline 1 & 20 & 0.375 & 90 & 20 & 0.39146 & 90 & 0.00 & 4.39 & 0.00 \\
\hline 2 & 31 & 0.25 & 45 & 31 & 0.23780 & 45 & 0.00 & 4.88 & 0.00 \\
\hline 3 & 50 & 0.1 & 45 & 49 & 0.12001 & 45 & 2.00 & 20.01 & 0.00 \\
\hline 4 & 25 & 0.125 & 45 & 27 & 0.11725 & 45 & 8.00 & 6.20 & 0.00 \\
\hline 5 & 21 & 0.225 & 90 & 22 & 0.22614 & 90 & 4.76 & 0.51 & 0.00 \\
\hline 6 & 19 & 0.45 & 90 & 22 & 0.49150 & 90 & 15.79 & 9.22 & 0.00 \\
\hline 7 & 49 & 0.225 & 45 & 49 & 0.22591 & 45 & 0.00 & 0.40 & 0.00 \\
\hline 8 & 17 & 0.3 & 45 & 17 & 0.29535 & 45 & 0.00 & 1.55 & 0.00 \\
\hline
\end{tabular}

Based on the comparison result, it is clear to draw that the proposed method based on Kriging surrogate model and an improved NSGA-III can identify the crack parameters of operating rotors more accurately with fewer samples than ANN.

\section{Conclusions}

A new crack parameters identification method based on a Kriging surrogate model and an improved NSGA-III is presented in the paper. The numerical results clearly show that the proposed approach can identify the crack location, depth, and angle for operating rotors accurately and efficiently.
(1) The $1 \mathrm{X}$ and $2 \mathrm{X}$ superharmonic components amplitudes of a rotor-bearing system in $1 / 3$ subcritical speed region can be selected as the index vectors for crack parameters identification.

(2) Crack parameters and their corresponding $1 \mathrm{X}$ and $2 \mathrm{X}$ amplitudes of vibration response for rotors are used to establish the Kriging surrogate model, which avoids complicated finite element calculation, demanding a large number of iterative steps.

(3) NSGA-III is improved by adding the preprocessing of population members to avoid the disadvantages of the original NSGA-III for crack parameters identification, which can improve the accuracy of crack 
parameters identification and speed up the convergence of the multiobjective function values.

(4) Compared with ANN, the proposed method can identify crack parameters for operating rotors more accurately with fewer samples.

It should be noted that only one crack is considered in this paper. There may be multiple cracks in rotors, and identification of multiple crack parameters is more complicated and requires further study.

\section{Data Availability}

All data generated or analyzed during this study are included in this published article.

\section{Conflicts of Interest}

The authors declare that there are no conflicts of interest regarding the publication of this paper.

\section{Acknowledgments}

This study was supported by the National Natural Science Foundation of China (no. 51875482).

\section{References}

[1] N. Bachschmid, P. Pennacchi, and E. Tanzi, Cracked Rotors: a Survey on Static and Dynamic Behaviour including Modelling and Diagnosis, Springer Science and Business Media, Berlin, Germany, 2010.

[2] A. Bovsunovsky and C. Surace, "Non-linearities in the vibrations of elastic structures with a closing crack: a state of the art review," Mechanical Systems and Signal Processing, vol. 62-63, pp. 129-148, 2015.

[3] C. A. Papadopoulos, "The strain energy release approach for modeling cracks in rotors: a state of the art review," $\mathrm{Me}$ chanical Systems and Signal Processing, vol. 22, no. 4, pp. 763-789, 2008.

[4] G. Sabnavis, R. G. Kirk, M. Kasarda, and D. Quinn, "Cracked shaft detection and diagnostics: a literature review," Shock and Vibration Digest, vol. 36, no. 4, pp. 287-296, 2004.

[5] A. D. Dimarogonas, "Vibration of cracked structures: a state of the art review," Engineering Fracture Mechanics, vol. 55, no. 5, pp. 831-857, 1996.

[6] H. Peng, Q. He, and Y. Zhen, "Stability analysis of a breathing cracked rotor with imposed mass eccentricity," Shock and Vibration, vol. 2015, Article ID 453216, 17 pages, 2015.

[7] H. B. Dong, X. F. Chen, B. Li, K. Y. Qi, and Z. J. He, "Rotor crack detection based on high-precision modal parameter identification method and wavelet finite element model," Mechanical Systems and Signal Processing, vol. 23, no. 3, pp. 869-883, 2009.

[8] Z. N. Haji and S. Olutunde Oyadiji, "The use of roving discs and orthogonal natural frequencies for crack identification and location in rotors," Journal of Sound and Vibration, vol. 333, no. 23, pp. 6237-6257, 2014.

[9] J. L. Zapico-Valle, E. Rodríguez, M. García-Diéguez, and J. L. Cortizo, "Rotor crack identification based on neural networks and modal data," Meccanica, vol. 49, no. 2, pp. 305-324, 2013.
[10] T. Yu, Q. K. Han, Z. Y. Qin, and B. C. Wen, "Identification of crack location and depth in rotating machinery based on artificial neural network," in Proceedings of International Symposium on Advances in Neural Networks (ISNN 2006), Part 3, vol. 3973, pp. 982-990, Chengdu, China, May-June 2006.

[11] J. Xiang, Y. Zhong, X. Chen, and Z. He, "Crack detection in a shaft by combination of wavelet-based elements and genetic algorithm," International Journal of Solids and Structures, vol. 45, no. 17, pp. 4782-4795, 2008.

[12] S. Prabhakar, A. S. Sekhar, and A. R. Mohanty, "Detection and monitoring of cracks in a rotor-bearing system using wavelet transforms," Mechanical Systems and Signal Processing, vol. 15, no. 2, pp. 447-450, 2001.

[13] S. K. Singh and R. Tiwari, "Detection and localization of multiple cracks in a stepped shaft," Fatigue and Fracture of Engineering Materials and Structures, vol. 36, no. 2, pp. 85-91, 2013.

[14] K. Saravanan and A. S. Sekhar, "Crack detection in a rotor by operational deflection shape and kurtosis using laser vibrometer measurements," Journal of Vibration and Control, vol. 19, no. 8, pp. 1227-1239, 2012.

[15] C. Zhang, B. Li, Z. Yang, W. Xiao, and Z. He, “Crack location identification of rotating rotor systems using operating deflection shape data," Science China Technological Sciences, vol. 56, no. 7, pp. 1723-1732, 2013.

[16] T. Ramesh Babu and A. S. Sekhar, "Detection of two cracks in a rotor-bearing system using amplitude deviation curve," Journal of Sound and Vibration, vol. 314, no. 3-5, pp. 457-464, 2008.

[17] Z. Lu, D. Dong, S. Cao, H. Ouyang, and C. Hua, "Multicrack localization in rotors based on proper orthogonal decomposition using fractal dimension and gapped smoothing method," Shock and Vibration, vol. 2016, Article ID 2375859, 17 pages, 2016.

[18] A. W. Lees, J. K. Sinha, and M. I. Friswell, "Model-based identification of rotating machines," Mechanical Systems and Signal Processing, vol. 23, no. 6, pp. 1884-1893, 2009.

[19] A. S. Sekhar, "Identification of a crack in a rotor system using a model-based wavelet approach," Structural Health Monitoring, vol. 2, no. 4, pp. 293-308, 2003.

[20] A. S. Sekhar, "Model-based identification of two cracks in a rotor system," Mechanical Systems and Signal Processing, vol. 18, no. 4, pp. 977-983, 2004.

[21] A. S. Sekhar, "Identification of unbalance and crack acting simultaneously in a rotor system: modal expansion versus reduced basis dynamic expansion," Journal of Vibration and Control, vol. 11, no. 9, pp. 1125-1145, 2005.

[22] R. Markert, R. Platz, and M. Seidler, "Model based fault identification in rotor systems by least squares fitting," International Journal of Rotating Machinery, vol. 7, no. 5, pp. 311-321, 2014.

[23] P. Pennacchi, N. Bachschmid, and A. Vania, "A model-based identification method of transverse cracks in rotating shafts suitable for industrial machines," Mechanical Systems and Signal Processing, vol. 20, no. 8, pp. 2112-2147, 2006.

[24] A. K. Darpe, "Coupled vibrations of a rotor with slant crack," Journal of Sound and Vibration, vol. 305, no. 1-2, pp. 172-193, 2007.

[25] Y. Lin and F. Chu, "The dynamic behavior of a rotor system with a slant crack on the shaft," Mechanical Systems and Signal Processing, vol. 24, no. 2, pp. 522-545, 2010.

[26] Y. Lin and F. Chu, "Numerical and experimental investigations of flexural vibrations of a rotor system with transverse or slant crack," Journal of Sound and Vibration, vol. 324, no. 1-2, pp. 107-125, 2009. 
[27] N. Bachschmid, P. Pennacchi, and E. Tanzi, "Some remarks on breathing mechanism, on non-linear effects and on slant and helicoidal cracks," Mechanical Systems and Signal Processing, vol. 22, no. 4, pp. 879-904, 2008.

[28] A. S. Sekhar, A. R. Mohanty, and S. Prabhakar, "Vibrations of cracked rotor system: transverse crack versus slant crack," Journal of Sound and Vibration, vol. 279, no. 3-5, pp. 12031217, 2005.

[29] K. Deb and H. Jain, "An evolutionary many-objective optimization algorithm using reference-point-based nondominated sorting approach, Part I: solving problems with box constraints," IEEE Transactions on Evolutionary Computation, vol. 18, no. 4, pp. 577-601, 2014.

[30] H. Jain and K. Deb, "An evolutionary many-objective optimization algorithm using reference-point based nondominated sorting approach, Part II: handling constraints and extending to an adaptive approach," IEEE Transactions on Evolutionary Computation, vol. 18, no. 4, pp. 602-622, 2014.

[31] J. Sacks, W. J. Welch, T. J. Mitchell, and H. P. Wynn, "Design and analysis of computer experiments," Statistical Science, vol. 4, no. 4, pp. 409-435, 1989.

[32] S. Sakata, F. Ashida, and M. Zako, "On applying Krigingbased approximate optimization to inaccurate data," Computer Methods in Applied Mechanics and Engineering, vol. 196, no. 13-16, pp. 2055-2069, 2007.

[33] Z. Yuan, F. Chu, and Y. Lin, "External and internal coupling effects of rotor's bending and torsional vibrations under unbalances," Journal of Sound and Vibration, vol. 299, no. 1-2, pp. 339-347, 2007.

[34] G. I. Giannopoulos, S. K. Georgantzinos, and N. K. Anifantis, "Coupled vibration response of a shaft with a breathing crack," Journal of Sound and Vibration, vol. 336, pp. 191-206, 2015.

[35] N. M. Newmark, "A method of computation for structural dynamics," Journal of Engineering Mechanics, vol. 85, no. 1, pp. 67-94, 1959.

[36] J.-J. Sinou, "Detection of cracks in rotor based on the $2 \times$ and $3 \times$ super-harmonic frequency components and the crackunbalance interactions," Communications in Nonlinear Science and Numerical Simulation, vol. 13, no. 9, pp. 2024-2040, 2008.

[37] C. Guo, J. Yan, and W. Yang, "Crack detection for a Jeffcott rotor with a transverse crack: an experimental investigation," Mechanical Systems and Signal Processing, vol. 83, pp. 260271, 2017.

[38] H. Y. Gao, X. L. Guo, and X. F. Hu, "Crack identification based on Kriging surrogate model," Structural Engineering and Mechanics, vol. 41, no. 1, pp. 25-41, 2012.

[39] H. Gao, X. Guo, H. Ouyang, and F. Han, "Crack identification of cantilever plates based on a Kriging surrogate model," Journal of Vibration and Acoustics, vol. 135, no. 5, article 051012, 2013.

[40] W. X. Ren and H. B. Chen, "Finite element model updating in structural dynamics by using the response surface method," Engineering Structures, vol. 32, no. 8, pp. 2455-2465, 2010.

[41] Y. H. Gao and X. C. Wang, "A sequential optimization method with multi-point sampling criterion based on kriging surrogate model," in Engineering Mechanics, New Age International Ltd., New Delhi, India, 2012.

[42] M. D. Mckay, R. J. Beckman, and W. J. Conover, "A comparison of three methods for selecting values of input variables in the analysis of output from a computer code," Technometrics, vol. 42, no. 1, pp. 55-61, 2000. 


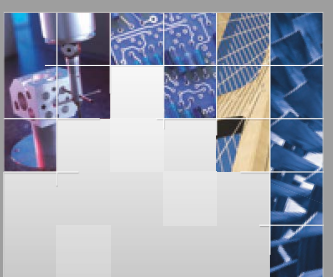

\section{Enfincering}
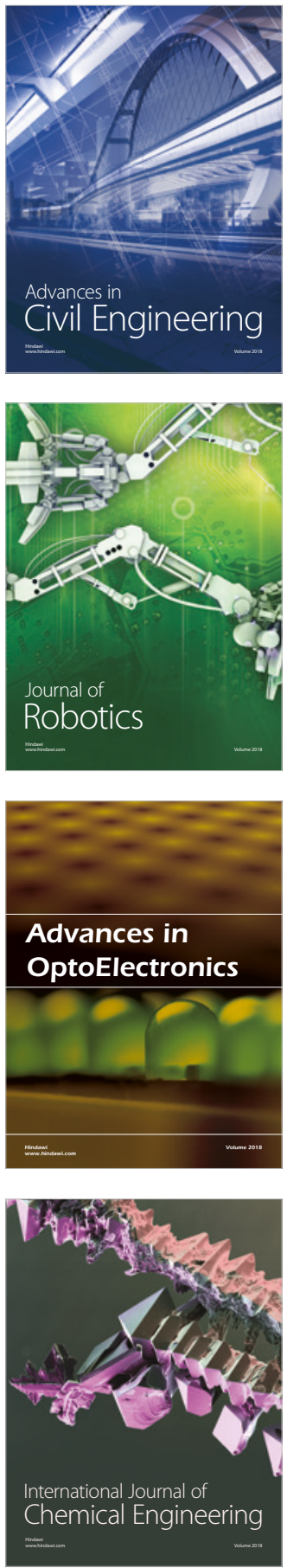

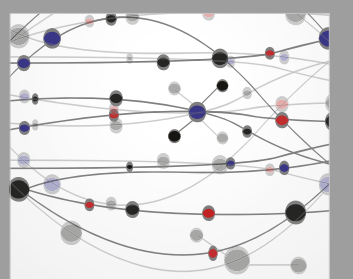

\section{Rotating \\ Machinery}

The Scientific World Journal

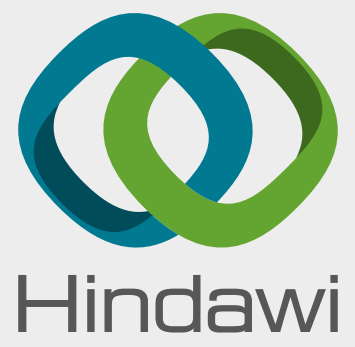

Submit your manuscripts at

www.hindawi.com
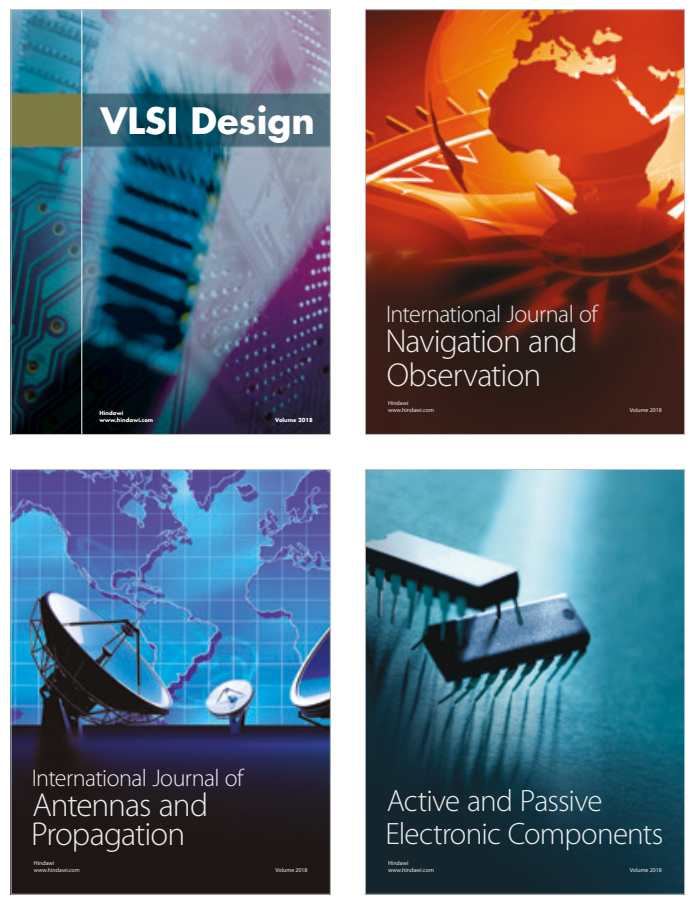
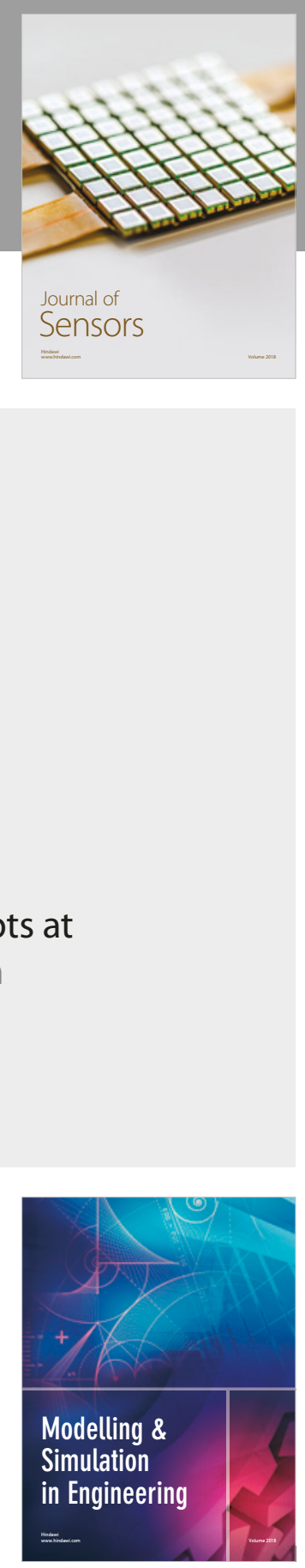

\section{Advances \\ Multimedia}
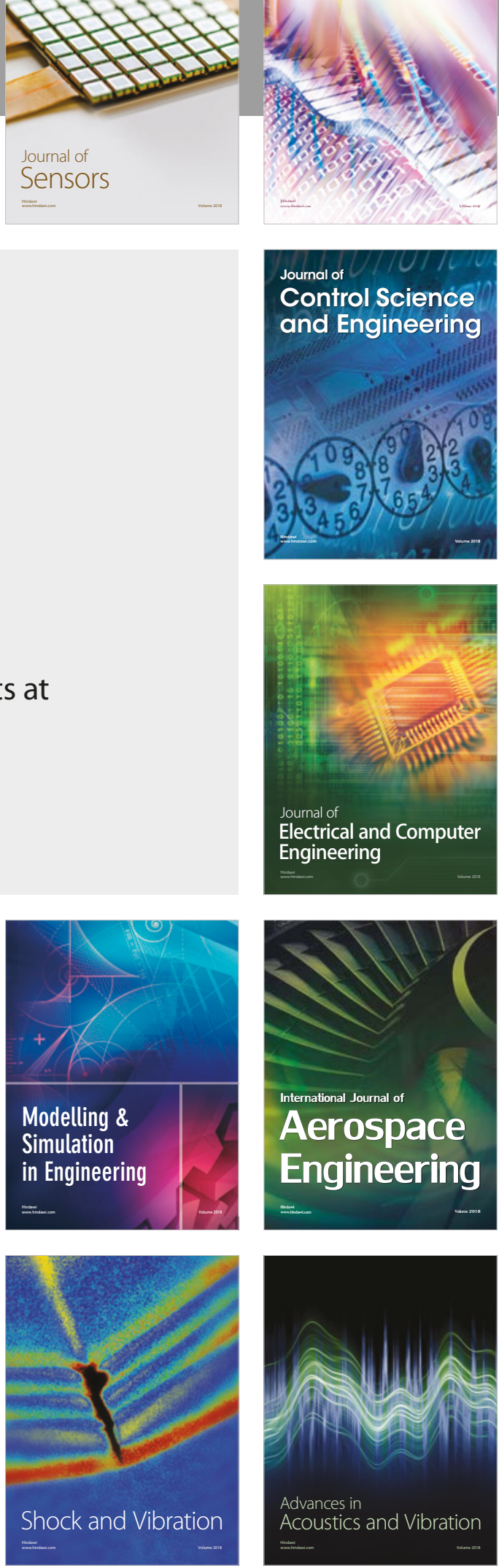